\title{
Signals of seminal vesicle autoantigen suppresses bovine serum albumin-induced capacitation in mouse sperm
}

\author{
Yen Hua Huang a,*, Shin Peih Kuo a , Mei Hsiang Lin ${ }^{a}$, Chwen Ming Shih ${ }^{\text {a }}$, \\ Sin Tak Chu ${ }^{\mathrm{b}, \mathrm{c}}$, Chih Chun Wei ${ }^{\mathrm{a}}$, Tasi Jung Wu ${ }^{\mathrm{a}}$, Yee Hsiung Chen ${ }^{\mathrm{b}, \mathrm{c}, *}$ \\ ${ }^{a}$ Department of Biochemistry and Graduate Institute of Medical Sciences, School of Medicine, Taipei Medical University, Taipei, Taiwan \\ ${ }^{\mathrm{b}}$ Institute of Biochemical Sciences, College of Science, National Taiwan University, Taiwan \\ ${ }^{\mathrm{c}}$ Institute of Biological Chemistry, Academia Sinica, Taipei, Taiwan
}

Received 14 September 2005

Available online 2 November 2005

\begin{abstract}
Capacitation is the prerequisite process for sperm to gain the ability for successful fertilization. Unregulated capacitation will cause sperm to undergo a spontaneous acrosome reaction and then fail to fertilize an egg. Seminal plasma is thought to have the ability to suppress sperm capacitation. However, the mechanisms by which seminal proteins suppress capacitation have not been well understood. Recently, we demonstrated that a major seminal vesicle secretory protein, seminal vesicle autoantigen (SVA), is able to suppress bovine serum albumin (BSA)-induced mouse sperm capacitation. To further identify the mechanism of SVA action, we determine the molecular events associated with SVA suppression of BSA's activity. In this communication, we demonstrate that SVA suppresses the BSA-induced increase of intracellular calcium concentration $\left(\left[\mathrm{Ca}^{2+}\right]_{\mathrm{i}}\right)$, intracellular $\mathrm{pH}\left(\mathrm{pH}_{\mathrm{i}}\right)$, the cAMP level, PKA activity, protein tyrosine phosphorylation, and capacitation in mouse sperm. Besides, we also found that the suppression ability of SVA against BSA-induced protein tyrosine phosphorylation and capacitation could be reversed by dbcAMP (a cAMP agonist).
\end{abstract}

(C) 2005 Elsevier Inc. All rights reserved.

Keywords: Capacitation; Seminal vesicle; $\mathrm{Ca}^{2+}$; Protein tyrosine phosphorylation; cAMP-PKA pathway

During epididymal transit, sperm progressively acquire the ability to move, but they are still fertilization incompetent. Fertilization capacity is gained after residence in the female reproductive tract for a finite period of time, and the physiological changes in sperm during this period are collectively called "capacitation." Capacitation is a complex process first described and defined independently by Chang $[1,2]$ and Austin [3,4]. The capacitation processes involve changes in membrane properties and dynamics, enzyme activities, elevation of $\left[\mathrm{Ca}^{2+}\right] \mathrm{i}, \mathrm{pH}_{\mathrm{i}}$, and the cAMP level. It leads to energy consumption and hypermotility, and eventually an acrosome reaction by sperm $[5,6]$.

\footnotetext{
* Corresponding authors. Fax: +886 2 2736166x3150 (Y.H. Huang), +886223635038 (Y.H. Chen).

E-mail addresses: rita1204@tmu.edu.tw (Y.H. Huang), bc304@gate. sinica.edu.tw (Y.H. Chen).
}

Sperm capacitation occurs in the oviduct or uterus, depending on the species [6]. The process of sperm capacitation is tightly regulated by suppression factors (in the epididymis and seminal vesicles) and capacitation factors (in the female reproductive tract). Serum albumin is abundant in the female reproductive tract. It is thought to serve as a cholesterol-binding protein to remove sperm membrane cholesterol, by which to destabilize the sperm membrane and induce sperm capacitation [7-9]. Serum albumin has also been demonstrated to regulate the T-type $\mathrm{Ca}^{2+}$ channel of sperm, induce extracellular $\mathrm{Ca}^{2+}$ and bicarbonate ion influx $[10]$, and elevate $\left[\mathrm{Ca}^{2+}\right]_{\mathrm{i}}$ and $\mathrm{pH}_{\mathrm{i}}$. The increase of $\left[\mathrm{Ca}^{2+}\right]_{\mathrm{i}}$ and $\mathrm{pH}_{\mathrm{i}}$ upregulates the cAMP-dependent signaling and enhances the protein tyrosine phosphorylation, ultimately inducing hyperactivation and capacitation of sperm [5,11].

The suppressive effect of capacitation by suppression factors is referred to as "decapacitation" [12]. Without suppression regulation, most of the sperm would undergo a 
spontaneous acrosome reaction. An acrosome-reacted sperm lose its acrosome cap which is required for sperm binding to the zona pellucida of the egg. Thus, sperm ultimately lose their fertilization ability even though they still have hypermotility [6]. It has been reported that the epididymis and seminal plasma contain decapacitation activity [12-23]; the presence of suppression factors (decapacitation factors) may prevent the unfruitful capacitation of sperm and allow effective fertilization of an egg at the right time and place [17]. Currently, several decapacitation factors are known. Fraser et al. [18] suggested that the decapacitation mechanism involves fucose residues and a GPI-anchored receptor on sperm in the epididymis. A low molecular weight $\mathrm{N}$-glycosidically linked oligomannosidic glycopeptide (MGp) isolated from the autoproteolysis products of human seminal plasma was reported to prevent premature sperm exocytosis [19]. Studies by Villemure et al. [21] revealed the gelatin-binding proteins from goat seminal plasma play a role in sperm decapacitation. A sperm adhesin family of boar accessory sex gland fluids is also supposed to consist of decapacitation factors [22]. In addition, the platelet-activation factor, acetylhydrolase (PAF-AH), was also suggested to play a role in decapacitation by hydrolysis of PAF to lyso-PAF [23]. However, the mechanisms of these potential factors in decapacitation have not been well defined.

Recently, we demonstrated that serum obtained from male and female mice immunized with seminal vesicle secretion (SVS) fluid is immunoreactive to an androgen-responsive glycoprotein $[24,25]$, and it was designated seminal vesicle autoantigen (SVA). SVA is a $19-\mathrm{kDa}$ protein secreted from luminal epithelium cells of seminal vesicles and contribute to the dominant component of seminal plasma $(\sim 300 \mu \mathrm{M})$ [26]. SVA binds $\mathrm{Zn}^{2+}$ [27] and choline-containing phospholipids, such as phosphatidylcholine and sphingomyelin [26]. SVA has been demonstrated to suppress BSA-induced zinc ion removal from the sperm membrane, sperm hypermotility, protein tyrosine phosphorylation, and capacitation [28]. In this communication, we further demonstrate that SVA suppresses BSA-induced $\left[\mathrm{Ca}^{2+}\right]_{\mathrm{i}}, \mathrm{pH}_{\mathrm{i}}$, the cAMP level, and PKA activity in mouse sperm. In addition, the suppressive effects of SVA on BSA-induced protein tyrosine phosphorylation and capacitation in mouse sperm can be reversed by a cAMP agonist.

\section{Materials and methods}

Materials. Fatty acid-free BSA, polyvinylalcohol, and Kemptide (LeuArg-Arg-Ala-Ser-Leu-Gly) were from Sigma (St. Louis, MO). Antiphosphotyrosine monoclonal antibody (clone 4G10) was from UBI (Lake Placid, NJ), horseradish peroxidase (HRP)-conjugated anti-mouse IgG was from Jackson ImmunoResearch Lab (West Grove, PA), Percoll, chemiluminescence detection ECL plus, $\left[\gamma_{-}{ }^{32} \mathrm{P}\right] \mathrm{ATP}$, and the cAMP assay kit (RPN 255) were from Amersham-Pharmacia Biotech (Buckinghamshire, UK), Fluo-3-AM and BCECF-AM were from Molecular Probes (Eugene, OR), dituylryl cAMP (dbcAMP), Rp-cAMPS, and IBMX were from Research Biochemicals International (Natick, MA), and H-89 was from LC Laboratories (Woburn, MA). Phosphocellulose Units SpinZyme Format for the radioactive kinase assay was from Pierce (Rockford, IL), and the scintillation counting cocktail was from Merck (Darmstadt, Germany). All other chemicals were of reagent grade.

Sperm preparation and cytological observations. Outbred CD-1 mice purchased from Charles River Laboratories (Wilmington, MA) were bred in the Animal Center at Taipei Medical University School of Medicine. Animals were handled in accordance with institutional guidelines on animal experimentations.

The culture medium used throughout these studies was modified Krebs-Ringer bicarbonate HEPES medium (HM) as described previously [28]. In brief, modified $\mathrm{HM}$ contains $120.0 \mathrm{mM} \mathrm{NaCl}, 2.0 \mathrm{mM} \mathrm{KCl}$, $1.20 \mathrm{mM} \mathrm{MgSO}{ }_{4} \cdot 7 \mathrm{H}_{2} \mathrm{O}, 0.36 \mathrm{mM} \mathrm{NaH}_{2} \mathrm{PO}_{4}, 15 \mathrm{mM} \mathrm{NaHCO}, 10 \mathrm{mM}$ Hepes, $5.60 \mathrm{mM}$ glucose, $1.1 \mathrm{mM}$ sodium pyruvate, and $1.7 \mathrm{mM} \mathrm{CaCl}$. The $\mathrm{pH}$ of the medium was adjusted to 7.3-7.4 with humidified air $/ \mathrm{CO}_{2}$ (95:5) in an incubator at $37^{\circ} \mathrm{C}$ for $48 \mathrm{~h}$ before use. Polyvinylalcohol $(1 \mathrm{mg} /$ $\mathrm{ml}$ ) was added to serve as a sperm protectant. Mature mouse sperm were harvested by a swim-up procedure from the caudal epididymides and isolated with a $20-80 \%$ Percoll gradient. The viability and progressive motility of the sperm fraction used in the present study were more than $95 \%$. The population of the capacitated stage in sperm was analyzed by the CTC staining method as described previously [29].

Flow cytometry. $\left[\mathrm{Ca}^{2+}\right]_{\mathrm{i}}$ of sperm was determined using fluo-3 AM by flow cytometry (FACScan, BD). In brief, Percoll-separated sperm were loaded with fluo-3 AM $(10 \mu \mathrm{M})$ for $10 \mathrm{~min}$. After $10 \mathrm{~min}$ incubation, sperm were washed twice with modified $\mathrm{HM}$ to remove any free fluo-3 AM. Fluo-3 AM-loaded sperm $\left(10^{6}\right.$ cells $\left./ \mathrm{ml}\right)$ were treated with SVA $(0-$ $66 \mu \mathrm{M})$ in the presence or absence of BSA $(0.3 \%)$ at $37^{\circ} \mathrm{C}$ for $90 \mathrm{~min}$ and then analyzed by epifluorescence microscope and flow cytometry.

$\mathrm{pH}_{\mathrm{i}}$ of sperm was determined using BCECF-AM. In brief, Percoll-separated sperm were loaded with BCECF-AM $(2 \mu \mathrm{M})$ for 10 min and then sperm were washed twice with modified HM to remove any free fluore. The fluore-loaded sperm were treated with $\operatorname{BSA}(0.3 \%) \pm \operatorname{SVA}(2,20$, and $66 \mu \mathrm{M})$ and then analyzed by flow cytometry. For $\mathrm{pH}_{\mathrm{i}}$ calibration, a nigericin/high $\mathrm{K}^{+}$calibration protocol was used to derive the $\mathrm{pH}_{\mathrm{i}}$ values as described previously [30]. The fluorescence of fluo-3 was excited at $488 \mathrm{~nm}$ and measured via a 515-540 nm filter, and the fluorescence of BCECF was excited at $510 \mathrm{~nm}$ and measured via a 564-606 nm filter. PMT voltages and gains were set to optimize the dynamic range of the signal. The fluorescence intensity of sperm was quantified for 10,000 individual cells.

cAMP assay. The amount of cAMP produced in living, intact sperm was determined using a nonradioactive enzyme immunoassay kit according to the manufacturer's instructions.

Assay of protein kinase A activity. Protein kinase A activity was measured using Kemptide (Leu-Arg-Arg-Ala-Ser-Leu-Gly) as the specific substrate. Sperm $\left(10^{7}\right.$ cells $\left./ \mathrm{ml}\right)$ were incubated under different experimental conditions, such as BSA $(0.3 \%)$, SVA $(66 \mu \mathrm{M})$ or BSA supplemented with SVA. DbcAMP (a cAMP agonist, $1 \mathrm{mM}$ ) plus IBMX (a phosphodiesterase inhibitor, $100 \mu \mathrm{M}$ ) were used to be a positive control, and H-89 (a PKA inhibitor, $30 \mu \mathrm{M}$ ) served as a negative control. After incubation at $37^{\circ} \mathrm{C}$ for $90 \mathrm{~min}$, the sperm suspension $(10 \mu \mathrm{l})$ was mixed with an equal volume of $2 \times$ assay cocktail $(10 \mu \mathrm{l})$ and incubated at $37^{\circ} \mathrm{C}$ for additional $15 \mathrm{~min}$. The final concentration of the assay components was $100 \mu \mathrm{M}$ kemptide, $\left[\gamma_{-}{ }^{32} \mathrm{P}\right] \mathrm{ATP}$ $(6000 \mathrm{Ci} / \mathrm{mmol})\left(2 \times 10^{6} \mathrm{cpm} /\right.$ assay $), 100 \mu \mathrm{M}$ ATP, $1 \%$ (v/v) Triton X-100, $1 \mathrm{mg} / \mathrm{ml} \mathrm{BSA}, 10 \mathrm{mM} \mathrm{MgCl}_{2}, 40 \mathrm{mM} \beta$-glycerophosphate, $5 \mathrm{mM} p$-nitrophenyl phosphate, $10 \mathrm{mM}$ Tris- $\mathrm{HCl}(\mathrm{pH} 7.4), 10 \mu \mathrm{M}$ aprotinin, and $10 \mu \mathrm{M}$ leupeptin. The reactions were stopped by an equal volume of $20 \% \mathrm{TCA}$, and reaction mixtures were cooled on ice for $20 \mathrm{~min}$ and followed by centrifugation at $10,000 \mathrm{~g}$ at room temperature for $3 \mathrm{~min}$. Twenty-five microliter of the resultant mixture was applied onto an affinity support of the phosphocellulose unit and washed with $500 \mu \mathrm{l}$ of $75 \mathrm{mM}$ phosphoric acid for four times ( $10 \mathrm{~min} /$ each time). The washed-sample bucket was then transferred into a scintillation vial for counting.

Detection of protein tyrosine phosphorylation. Sperm $\left(5 \times 10^{6}\right.$ cells $\left./ \mathrm{ml}\right)$ were incubated with BSA $(0.3 \%)$ in the absence or presence of SVA $(66 \mu \mathrm{M})$. In some experiments, BSA and SVA supplemented with dbcAMP (a cAMP agonist, $1 \mathrm{mM}$ ) plus IBMX (a phosphodiesterase inhibitor, $100 \mu \mathrm{M}$ ), or BSA and H-89 (a PKA inhibitor, $30 \mu \mathrm{M}$ ) or RpcAMP (a cAMP antagonist, $1 \mathrm{mM}$ ) were added. The reactions were incubated at $37^{\circ} \mathrm{C}$. After $90 \mathrm{~min}$ incubation, the cell lysate was prepared 
according to Visconti et al. [31], subjected to a 10\% SDS-PAGE, and then transferred to a PVDF membrane for Western blot analysis. The monoclonal anti-phosphotyrosine $\mathrm{IgG}$ (clone $4 \mathrm{G} 10)(1 \mu \mathrm{g} / \mathrm{ml})$ was used as the primary antibody and HRP-conjugated anti-mouse $\operatorname{IgG}(1: 2000)$ served as the secondary antibody. The enzyme activity of HRP was detected by the ECL system according to the manufacturer's instructions.

Statistical analysis. All experiments were repeated at least three times with three different pooled sperm samples from four or five male mice. The data were expressed as means $\pm \mathrm{SD}$. Difference in means was assessed by one-way analysis of variance (ANOVA), followed by the Tukey-Kramer multiple comparisons test.

\section{Results}

SVA suppresses BSA-stimulated capacitation in mouse sperm

BSA, like serum albumin, is a well-known putative capacitation factor used for stimulating mouse sperm capacitation in vitro. Its related capacitation events involve the removal of membrane-bound zinc ions, elevation of $\left[\mathrm{Ca}^{2+}\right]_{\mathrm{i}}, \mathrm{pH}_{\mathrm{i}}$, the cAMP level, sperm hypermotility, and protein tyrosine phosphorylation [5]. To determine the molecular events of SVA suppression of sperm capacitation, we detected the SVA effect on BSA (0.3\%)-induced capacitation signaling. The capacitation states of mouse caudal epididymal sperm under different experimental conditions were determined by the CTC assay [29]. As shown in Fig. 1, fewer than $15 \%$ of sperm underwent capacitation in the absence of BSA with or without SVA. BSA $(0.3 \%)$ induced sperm capacitation by $53 \pm 8 \%$. SVA $(66 \mu \mathrm{M})$ suppressed BSA-induced capacitation in mouse sperm from $53 \pm 8 \%$ to $30 \pm 4 \%$. This effective concentration of SVA on BSA activity is well below the physiological concentration in semen $(\sim 300 \mu \mathrm{M})$. These observations further confirmed our previous report that SVA suppressed BSA-induced mouse sperm capacitation [28]. In addition, adding dbcAMP plus IBMX reversed the suppressive effect of SVA on BSA-induced mouse sperm capacitation, suggesting a role of cAMP in SVA suppression signaling.

\section{SVA suppresses BSA-induced elevation of $\left[\mathrm{Ca}^{2+}\right]_{i}$ and $\mathrm{pH}_{i}$ in mouse sperm}

Elevation of $\left[\mathrm{Ca}^{2+}\right]_{\mathrm{i}}$ and $\mathrm{pH}_{\mathrm{i}}$ has been shown to be associated with mouse sperm capacitation induced by BSA $[5,32]$. $\left[\mathrm{Ca}^{2+}\right]_{\mathrm{i}}$ and $\mathrm{pH}_{\mathrm{i}}$ have also been demonstrated to upregulate membrane/soluble adenylate cyclase activity, by which to produce cAMP, and activate PKA activity, inducing protein tyrosine phosphorylation and capacitation in mouse sperm [32]. Since SVA is capable of suppressing BSA-induced capacitation, we decided to determine the effect of SVA on $\left[\mathrm{Ca}^{2+}\right]_{\mathrm{i}}$ and $\mathrm{pH}_{\mathrm{i}}$ in sperm stimulated by BSA. $\left[\mathrm{Ca}^{2+}\right]_{\mathrm{i}}$ was determined by epifluorescence microscopy and flow cytometry using fluo-3-AM. As shown in Fig. 2A, BSA $(0.3 \%)$ increased $\left[\mathrm{Ca}^{2+}\right]_{\mathrm{i}}$ (Fig. 2A, panel b vs. panel a). SVA not only suppressed the BSA-induced elevation of $\left[\mathrm{Ca}^{2+}\right]_{\mathrm{i}}$ (Fig. 2A, panel d vs. panel b), but also

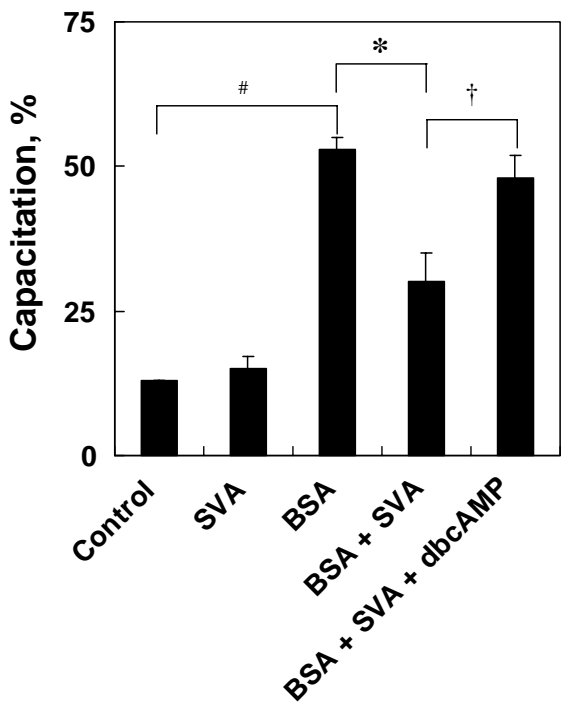

Fig. 1. cAMP agonist reverses SVA suppression of BSA-induced capacitation in mouse sperm. Capacitation stage of sperm $\left(5 \times 10^{6}\right.$ cells $\left./ \mathrm{ml}\right)$ under different experimental conditions was determined using the CTC fluorescence method. Each data point is the mean $\pm \mathrm{SD}$ of three independent determinations. Data obtained from sperm treated with BSA alone were compared with that of control sperm, or data obtained from sperm treated with BSA and SVA were compared with that of sperm treated with BSA but without SVA, or data obtained from sperm treated with BSA and SVA in the presence of dbcAMP plus IBMX were compared with that of sperm treated with BSA and SVA but in the absence of dbcAMP plus IBMX, respectively, by oneway ANOVA, Tukey-Kramer multiple comparison test. $\left({ }^{\#} p<0.001\right.$, $\left.{ }^{*} p<0.001,{ }^{\dagger} p<0.001\right)$.

decreased the basal $\left[\mathrm{Ca}^{2+}\right]_{\mathrm{i}}$ in mouse sperm (Fig. 2A, panel c vs. panel a). Besides, the relative $\left[\mathrm{Ca}^{2+}\right]_{i}$ of sperm was also detected by flow cytometry and expressed as percentages in comparison with that of control cells. As shown in Fig. 2B, BSA elevated $\left[\mathrm{Ca}^{2+}\right]_{\mathrm{i}}$ to $153 \pm 6 \%$. SVA suppressed $\left[\mathrm{Ca}^{2+}\right]_{\mathrm{i}}$ with or without BSA in a dose-dependent manner.

Elevation of $\mathrm{pH}_{\mathrm{i}}$ has been correlated with BSA-induced sperm capacitation [33]. To determine the SVA effect on $\mathrm{pH}_{\mathrm{i}}$ in mouse sperm, sperm pre-loaded with BCECF-AM were incubated with SVA and analyzed by flow cytometry. The $\mathrm{pH}_{\mathrm{i}}$ of sperm was estimated by a $\mathrm{pH}$ standard curve which was calibrated according to a $\mathrm{pH}$ 6-7 standard solution (Fig. 3A) as described previously [30]. As shown in Fig. 3B, BSA elevated the $\mathrm{pH}_{\mathrm{i}}$ from 6.5 to 6.9, and SVA suppressed the BSA-induced elevation of $\mathrm{pH}_{\mathrm{i}}$. At $20 \mu \mathrm{M}$, SVA significantly suppressed the BSA-induced elevation of $\mathrm{pH}_{\mathrm{i}}$ to basal level of mouse sperm. In addition, SVA was also shown to decrease the basal level of $\mathrm{pH}_{\mathrm{i}}$ of mouse sperm (our unpublished results).

\section{SVA suppresses BSA-induced elevation of the cAMP level in} mouse sperm

Since $\left[\mathrm{Ca}^{2+}\right]_{\mathrm{i}}$ and $\mathrm{pH}_{\mathrm{i}}$ have been shown to be the upstream regulators of adenylate cyclase activity, we then determined the effect of SVA on the BSA-induced elevation 

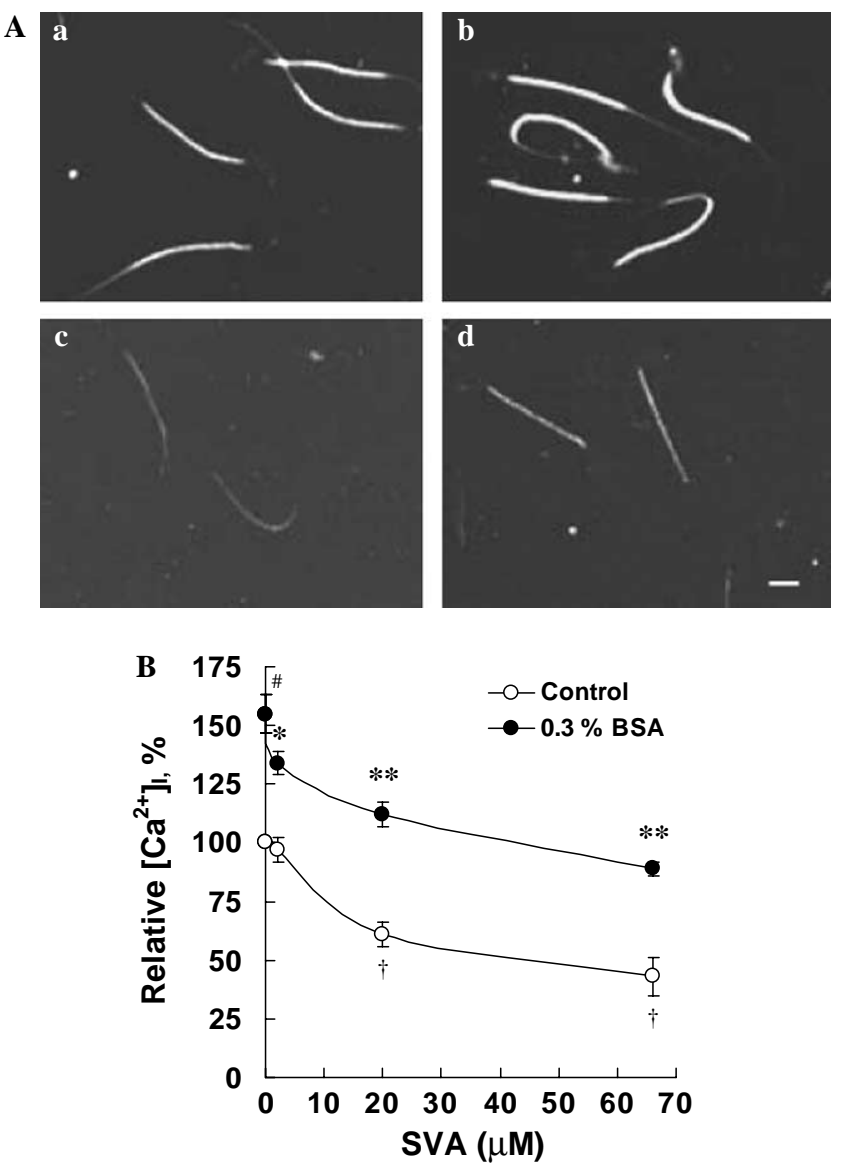

Fig. 2. SVA suppresses BSA-induced elevation of $\left[\mathrm{Ca}^{2+}\right]_{\mathrm{i}}$ in mouse sperm. Sperm $\left(5 \times 10^{6}\right.$ cells $\left./ \mathrm{ml}\right)$ were loaded with fluo-3 AM to detect $\left[\mathrm{Ca}^{2+}\right]_{\mathrm{i}}$. Fluorescence images of sperm under different experimental conditions were shown in (A): (a) control (HM only), (b) BSA (0.3\%), (c) SVA (66 $\mu \mathrm{M}$ ), and (d) BSA + SVA. Fluo-3-loaded sperm were incubated with increasing concentration of SVA $(0-66 \mu \mathrm{M})$ in the presence (closed circles) or absence (open circles) of BSA (B). After $90 \mathrm{~min}$ incubation, sperm were subjected to a flow cytometry to analyze $\left[\mathrm{Ca}^{2+}\right]_{\mathrm{i}}$. $\left[\mathrm{Ca}^{2+}\right]_{\mathrm{i}}$ of sperm was shown as percentages in comparison with that of control sperm. Each data point is the mean $\pm \mathrm{SD}$ of five independent determinations. Data obtained from sperm treated with BSA or SVA alone were compared with that of control sperm ( ${ }^{\dagger} p<0.001,{ }^{\#} p<0.001$ ), or data obtained from sperm treated with BSA and SVA were compared with that of sperm treated with BSA but without SVA $\left({ }^{*} p<0.01,{ }^{* *} p<0.001\right)$, respectively, by one-way ANOVA, Tukey-Kramer multiple comparison test. Scale bar, $10 \mu \mathrm{m}$.

of the cAMP level in mouse sperm. As shown in Fig. 4, BSA $(0.3 \%)$ increased the cAMP level to $153 \pm 11 \%$ as compared with that of control sperm. SVA suppressed the BSA-induced elevation of the cAMP level in a dose-dependent manner with the maximum effect at $66 \mu \mathrm{M}$ (from $153 \pm 11 \%$ to $93 \pm 10 \%)$. Besides, SVA $(66 \mu \mathrm{M})$ decreased the basal level of cAMP to $43 \pm 8 \%$ in mouse sperm. This observation is in coincidence with our previous results that SVA suppressed the basal $\left[\mathrm{Ca}^{2+}\right]_{\mathrm{i}}$ and $\mathrm{pH}_{\mathrm{i}}$.

\section{SVA suppresses BSA-induced the PKA activity in mouse sperm}

cAMP has been demonstrated to affect PKA activity and regulate protein tyrosine phosphorylation of mouse sperm [34]. Since SVA is able to suppress the BSA-induced elevation of the cAMP level in mouse sperm, we suggested that SVA may suppress the BSA-induced PKA activity. A PKA-specific substrate, Kemptide (Leu-Arg-Arg-Ala-SerLeu-Gly), was used to detect the PKA activity of sperm. As shown in Fig. 5, dbcAMP plus IBMX served as a positive control, it enhanced the PKA activity to near $400 \%$ as compared with that of the control sperm. A PKA inhibitor H-89 was used to be a negative control; it suppressed the PKA activity to $\sim 75 \%$. BSA $(0.3 \%)$ significantly enhanced the PKA activity to $155 \pm 6 \%$ and SVA both suppressed the BSA-induced and the basal level of PKA activity of sperm. These results support our previous observations that SVA suppresses both the BSA-induced and the basal $\left[\mathrm{Ca}^{2+}\right]_{\mathrm{i}}$ and the cAMP levels (Figs. 2-4). Furthermore, the suppressive effect of SVA $(200 \mu \mathrm{M})$ on the PKA activity of mouse sperm could be overcome by $10 \%$ BSA. This observation further supports our previous report that $10 \%$ BSA reversed the SVA's suppressive effect on $0.3 \%$ BSA-induced protein tyrosine phosphorylation and capacitation in mouse sperm [28].

\section{cAMP agonist reverses $S V A$ 's suppression of BSA- stimulated protein tyrosine phosphorylation in mouse sperm}

Protein tyrosine phosphorylation has been demonstrated to the molecular evidence of capacitation, and it is correlated with the cAMP level and PKA activity in mouse sperm [34]. Since SVA decreased the cAMP level in sperm, we therefore detected the effect of a cAMP agonist on SVA's suppression of BSA-induced protein tyrosine phosphorylation. As shown in Fig. 6A, two proteins of M.W. $\sim 120$ and $\sim 50 \mathrm{kDa}$ were tyrosine-phosphorylated in control sperm which showed normal motility. The M.W. $120-\mathrm{kDa}$ protein did not respond to the BSA stimulation and was similar to p95/106 hexokinase identified by Kalab et al. [35] (Fig. 6A, indicated by an arrowhead). BSA $(0.3 \%)$ treatment of sperm resulted in significant enhancement of protein tyrosine phosphorylation in the range of MW $50-100 \mathrm{kDa}$ (Fig. 6A, lane 3, indicated by arrows), and this phenomenon was suppressed by Rp-cAMP and H-89 (Fig. 6A, lanes 4 and 5). These results further confirm the previous report that the cAMP-PKA pathway is involved in BSA's activity of mouse sperm $[5,34]$. Treatment of sperm with SVA reduced motility [26] and the tyrosine phosphorylation of the MW $50 \mathrm{kDa}$ protein of control sperm (Fig. 6B, lane 2). Furthermore, the BSA-induced protein tyrosine phosphorylation of sperm was also significantly suppressed by SVA (Fig. 6B, lane 4).

DbcAMP and IBMX have been reported to induce protein tyrosine phosphorylation and capacitation in mouse sperm [34]. To define the role of cAMP in SVA's suppressive effect, we determined the effect of dbcAMP plus IBMX on SVA suppression of BSA-induced protein tyrosine phosphorylation. As shown in Fig. 6B, the suppressive effects of SVA on BSA-induced protein tyrosine phosphorylation were overcome in the presence of dbcAMP plus 

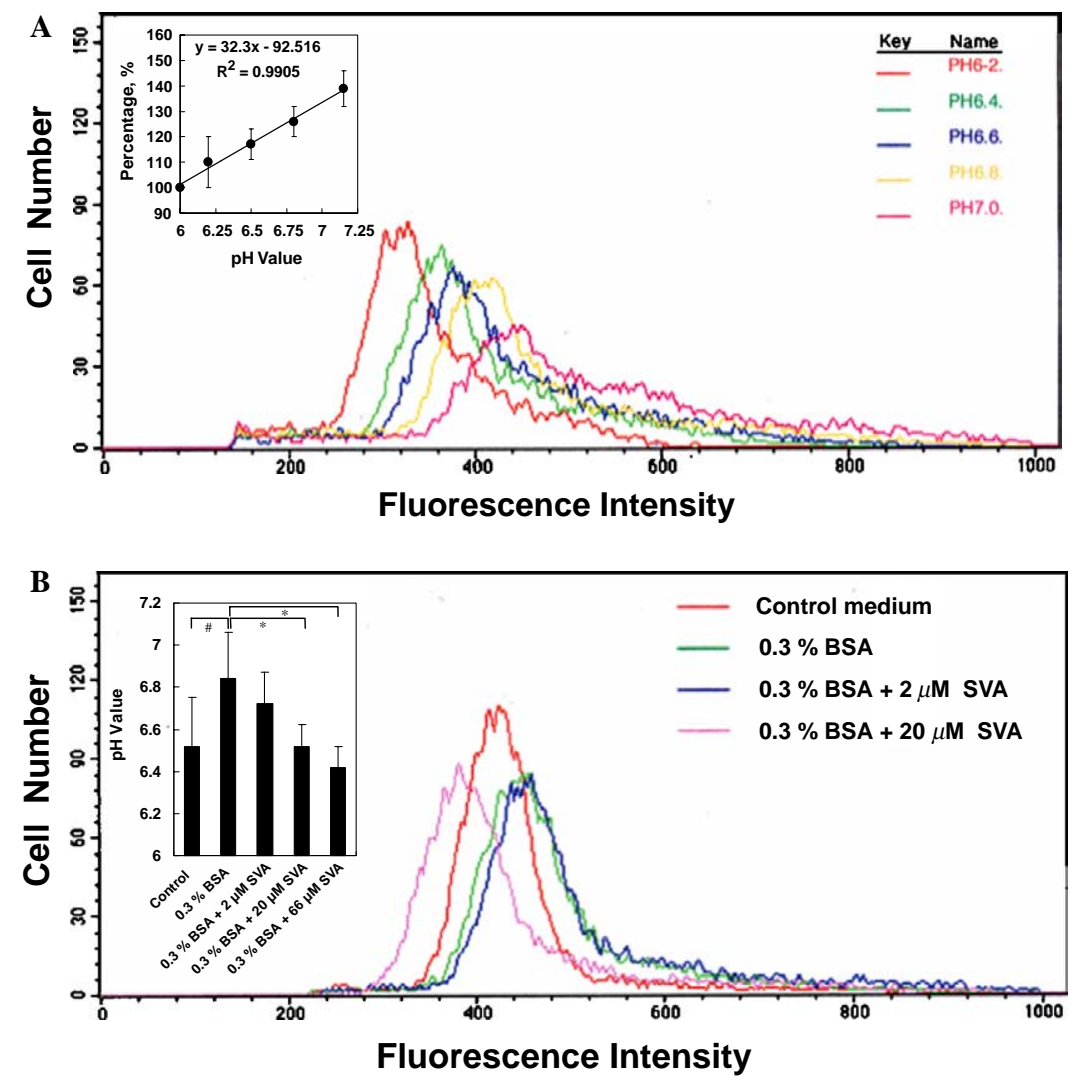

Fig. 3. SVA suppresses BSA-induced elevation of $\mathrm{pH}_{\mathrm{i}}$ in mouse sperm. Sperm $\left(5 \times 10^{6}\right.$ cells $\left./ \mathrm{ml}\right)$ pre-loaded with BCECF AM were calibrated with a pH 6-7 standard solution (A), or incubated with BSA $(0.3 \%)$ in the presence or absence of SVA $(2,20$, and $66 \mu \mathrm{M})(\mathrm{B})$. $\mathrm{pH}_{\mathrm{i}}$ of sperm under different experimental conditions are shown as percentages of that of control sperm. Each data point is the mean \pm SD of three independent determinations. Data obtained from sperm treated with BSA alone were compared with that of control sperm, or data obtained from sperm treated with BSA and SVA were compared with that of sperm treated with BSA but without SVA, respectively, by one-way ANOVA, Tukey-Kramer multiple comparison test. $\left({ }^{\#} p<0.001,{ }^{*} p<0.001\right)$.

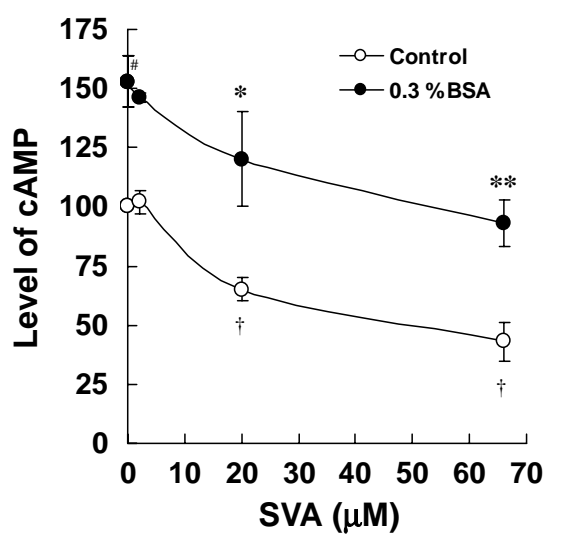

Fig. 4. SVA suppresses BSA-induced elevation of the cAMP level in mouse sperm. Sperm $\left(5 \times 10^{6}\right.$ cells $\left./ \mathrm{ml}\right)$ were incubated with increasing concentration of SVA $(0-66 \mu \mathrm{M})$ in the presence (closed circles) or absence (open circles) of BSA $(0.3 \%)$. After 90 min incubation, the total cell lysate was extracted and the total intracellular cAMP amount was detected. Each data point is the mean \pm SD of five independent determinations. Data obtained from sperm treated with BSA or SVA alone were compared with that of control sperm $\left({ }^{\#} p<0.001,{ }^{\dagger} p<0.001\right)$, or data obtained from sperm treated with BSA and SVA were compared with that of sperm treated with BSA but without SVA $\left({ }^{*} p<0.01,{ }^{* *} p<0.001\right)$, respectively, by one-way ANOVA, Tukey-Kramer multiple comparison test.
IBMX (Fig. 6B, lanes 5-7). This result further supports our previous observation that a cAMP agonist reversed SVA's suppression on capacitation of mouse sperm (Fig. 1). Together with the fact that SVA decrease the cAMP level and PKA activity, these observations strongly suggest that cAMP not only participates in BSA-induced protein tyrosine phosphorylation and capacitation but also involves in SVA's suppressive mechanism.

\section{Discussion}

Successful fertilization is tightly regulated by capacitation and decapacitation processes. Sperm interact with suppression factors in the seminal plasma (e.g., seminal plasma proteins) and capacitation factors in the female reproductive tract (e.g., serum albumin) while they are ejaculated from the caudal epididymis to move to the female reproductive tract. Serum albumin is thought to stimulate sperm capacitation in the female genital tract. In vitro, $\left[\mathrm{Ca}^{2+}\right]_{i}$ and $\mathrm{pH}_{\mathrm{i}}$ have been demonstrated to be the upstream mediators of BSA-induced mouse sperm capacitation. $\left[\mathrm{Ca}^{2+}\right]_{\mathrm{i}}$ and $\mathrm{pH}_{\mathrm{i}}$ regulate the membrane and/or cytosolic adenylate cyclase [5,36-39], modulate cAMP metabolism and PKA activity [36], and ultimately affect capacitation-associated 


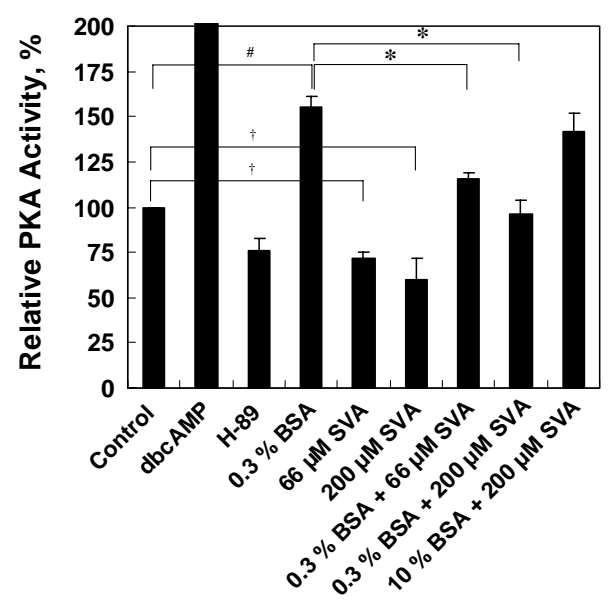

Fig. 5. SVA suppresses BSA-induced elevation of the PKA activity in mouse sperm. The PKA activities of sperm under different experimental conditions were determined, such as (1) control (HM only), (2) dbcAMP $(1 \mathrm{mM})+$ IBMX $(100 \mu \mathrm{M})$, (3) H-89 $(30 \mu \mathrm{M})$, (4) BSA (0.3\%), (5) SVA $(66 \mu \mathrm{M})$, (6) SVA $(200 \mu \mathrm{M}),(7)$ BSA $(0.3 \%)+$ SVA $(66 \mu \mathrm{M})$, (8) BSA $(0.3 \%)+$ SVA $(200 \mu \mathrm{M})$, and $(9)$ BSA $(10 \%)+$ SVA $(200 \mu \mathrm{M})$. Each data point is the mean $\pm \mathrm{SD}$ of three-independent determinations. Data obtained from sperm treated with BSA or SVA alone were compared with that of control sperm, or data obtained from sperm treated with BSA and SVA were compared with that of sperm treated with BSA but without SVA, respectively, by one-way ANOVA, Tukey-Kramer multiple comparison test. $\left({ }^{\#} p<0.001,{ }^{*} p<0.001,{ }^{\dagger} p<0.001\right)$.

protein tyrosine phosphorylation of sperm $[32,40]$. Stimulation of tyrosine phosphorylation is an important event during mammalian sperm capacitation [34,41]. In somatic cells, the tyrosine-phosphorylated proteins mediate a variety of cellular functions such as growth regulation, cell cycle control, cytoskeletal assembly, ionic current regulation, and receptor regulation [42]. In human sperm, the capacitation-associated tyrosine-phosphorylated proteins have been demonstrated to involve the valosin-containing protein (VCP), SNARE-interacting protein and protein kinas A-anchoring protein family, etc., suggesting the changes in regulatory enzymes of acrosomes and cytoskeletal elements during the sperm capacitation process [43].

An unregulated capacitation process causes sperm to undergo unfruitful capacitation prior to reaching the egg for fertilization. Seminal plasma is thought to contain some suppressive factors to regulate the capacitation processes $[12,14-17,19-23,44-46]$. The accessory sexual organ is also thought to play a role in maintaining an optimal calcium environment in seminal plasma, by which to regulate sperm function [45]. In supporting this hypothesis, Coronel et al. [46] reported that a calcium transport inhibitor, caltrin, is secreted by bovine seminal vesicles and binds with sperm to maintain sperm in a low cytosolic calcium concentration during ejaculation. In our results, as a major component of seminal plasma, SVA significantly suppresses BSA-induced mouse sperm capacitation and its related signaling. The SVA-affected molecular events include $\left[\mathrm{Ca}^{2+}\right]_{\mathrm{i}}, \mathrm{pH}_{\mathrm{i}}$, the cAMP level, PKA activity, and protein tyrosine phosphorylation. The observations that SVA decreases $\left[\mathrm{Ca}^{2+}\right]_{\mathrm{i}}$ and the cAMP level in sperm are in coincidence with our previous studies that SVA suppresses sperm motility [26]. The $\mathrm{IC}_{50}$ of SVA suppression on BSA-induced $\left[\mathrm{Ca}^{2+}\right]_{\mathrm{i}}$ and the cAMP level was less than $20 \mu \mathrm{M}$, a concentration which is well below the physiological concentration of SVA in semen $(\sim 300 \mu \mathrm{M})$.

Since $\mathrm{Ca}^{2+}$ is the upstream regulator of sperm capacitation, the fact that $\left[\mathrm{Ca}^{2+}\right]_{\mathrm{i}}$ decreases apparently plays an important role in SVA's activity. We hypothesized that there are two possibilities for SVA suppression of $\left[\mathrm{Ca}^{2+}\right]_{\mathrm{i}}$ of mouse sperm. SVA may block the calcium influx or SVA may play a role in calcium clearance of mouse sperm. The calcium influx may not be affected by SVA because SVA is effective in lowering $\left[\mathrm{Ca}^{2+}\right]_{\mathrm{i}}$ in $\mathrm{Ca}^{2+}$-free medium as well as in $\mathrm{Ca}^{2+}$-containing medium (unpublished results). Besides, in view of

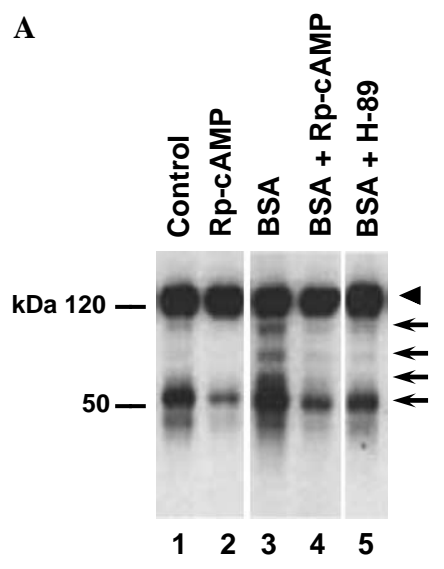

B
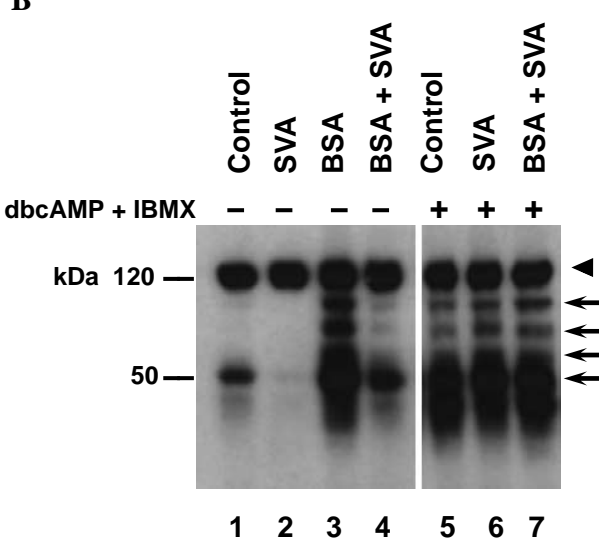

Fig. 6. cAMP agonist reverses the SVA inhibition of BSA-induced protein tyrosine phosphorylation in mouse sperm. The pattern of protein tyrosine phosphorylation in mouse sperm $\left(5 \times 10^{6}\right.$ cells $\left./ \mathrm{ml}\right)$ incubated in different experimental conditions was detected (A): (1) control (HM only), (2) Rp-cAMP $(1 \mathrm{mM})$, (3) BSA $(0.3 \%)$, (4) BSA + Rp-cAMP, and (5) BSA + H-89 $(30 \mu \mathrm{M})$. The suppressive effect of SVA on BSA-induced protein tyrosine phosphorylation was detected and is shown in (B): (1) control (HM only), (2) SVA (66 $\mu \mathrm{M})$, (3) BSA (0.3\%), (4) BSA + SVA, and (5-7) BSA + SVA + cAMP agonist (dbcAMP plus IBMX). The arrows indicate the location of capacitation-related tyrosine-phosphorylated proteins, and the arrowhead denotes the location of a capacitation-unrelated $120 \mathrm{kDa}$ tyrosine-phosphorylated protein. 
intracellular $\mathrm{Ca}^{2+}$ clearance, there are four major mechanisms that have been reported in most cell types [47]. Two are on the plasma membrane: the plasma membrane $\mathrm{Ca}^{2+}$ ATPase (PMCA, which exports a cytoplasmic $\mathrm{Ca}^{2+}$ ion while importing one or two extracellular protons), and the plasma membrane $\mathrm{Na}^{2+}-\mathrm{Ca}^{2+}$ exchanger (NCX, which exports an intracellular $\mathrm{Ca}^{2+}$ ion and imports approximately three $\mathrm{Na}^{+}$ions). The other two clearance sites are in the intracellular organelles: sarcoplasmic endoplasmic reticulum $\mathrm{Ca}^{2+}$-ATPase (SERCA pumps) and mitochondrial $\mathrm{Ca}^{2+}$ uniporter (MCU). In mouse sperm, PMCA and NCX are considered to be the most important molecules for maintaining low $\left[\mathrm{Ca}^{2+}\right]_{\mathrm{i}}$, but MCU just play a minor role and the SERCA pumps are not thought to be essential in mediating $\mathrm{Ca}^{2+}$ clearance in sperm [47]. In consideration of that SVA decreases both the BSA-induced and basal $\left[\mathrm{Ca}^{2+}\right]_{\mathrm{i}}$ and $\mathrm{pH}_{\mathrm{i}}$ (Figs. 2 and 3) and the PMCA's dominant role in exporting $\mathrm{Ca}^{2+}$ and importing extracellular protons, we suggest PMCA is likely the site where SVA exerts its action. However, this hypothesis needs to be further examined.

BSA and SVA are both phospholipid binding proteins. The interactions of BSA and SVA with sperm membrane lipid components may play roles in regulating capacitation signaling. Recent studies by Sleight et al. [48] conclude that BSA-induced cholesterol efflux alters the lipid raft domain on sperm membrane, by which to initiate the capacitation signaling. Lipid rafts are highly enriched in cholesterol, gangliosides, and sphingolipids, and are thought to recruit specific types of proteins to serve as the cholesterol traffic centers for signal transduction pathway originating at the plasma membrane [49]. PMCA has also been shown to be concentrated in the caveolae/raft and mediated by sphingolipids [50]. As SVA is capable of binding choline-containing phospholipids and sphingolipid [26], the possible interaction of SVA with these specific phospholipids/sphingolipids on sperm membrane lipid-rafts may mediate the $\mathrm{Ca}^{2+}$ signal to suppress the BSA-induced capacitation in mouse sperm. This suppressive effect of SVA (in semen) on capacitation may enable sperm to avoid unfruitful capacitation before encountering the egg. Sperm may undergo capacitation at or near the site where the egg resides, and the concentration of SVA is low in the uterus and oviduct.

\section{Acknowledgments}

This work was supported by grants from National Science Council, Taiwan NSC91-2320-B-038-029 and NSC93-2311-B-038-006 (to Y.H.H.), and NSC91-2311B001-076 and NSC91-2311-B002-049 (to Y.H.C.), and from Taipei Medical University, TMU92-AE1-B24 and 94TMU-TMUH-03 (to Y.H.H.).

\section{References}

[1] M.C. Chang, Fertilizing capacity of spermatozoa deposited into the fallopian tubes, Nature 168 (1951) 697-698.
[2] M.C. Chang, Development of fertilizing capacity of rabbit spermatozoa in the uterus, Nature 175 (1955) 1036-1037.

[3] C.R. Austin, Observations on the penetration of the sperm in the mammalian egg, Aust. J. Sci. Res. B 4 (1951) 581-596.

[4] C.R. Austin, The capacitation of the mammalian sperm, Nature 170 (1952) 326.

[5] P.E. Visconti, G.S. Kopf, Regulation of protein phosphorylation during sperm capacitation, Biol. Reprod. 59 (1998) 1-6.

[6] R. Yanagimachi, The Physiology of Reproduction, Raven, New York, 1994.

[7] N.L. Cross, Role of cholesterol in sperm capacitation, Biol. Reprod. 59 (1998) 7-11.

[8] B.K. Davis, R. Byrne, K. Bedigian, Studies on the mechanism of capacitation: albumin-mediated changes in plasma membrane lipids during in vitro incubation of rat sperm cells, Proc. Natl. Acad. Sci. USA 77 (1980) 1546-1550.

[9] K.J. Go, D.P. Wolf, Albumin-mediated changes in sperm sterol content during capacitation, Biol. Reprod. 32 (1985) 145-153.

[10] F. Espinosa, I. Lopez-Gonzalez, C. Munoz-Garay, R. Felix, J.L. De La Vega-Beltran, G.S. Kopf, P.E. Visconti, A. Darszon, Dual regulation of the T-type $\mathrm{Ca}(2+)$ current by serum albumin and beta-estradiol in mammalian spermatogenic cells, FEBS Lett. 475 (2000) 251-256.

[11] S. Tardif, L. Lefievre, C. Gagnon, J.L. Bailey, Implication of cAMP during porcine sperm capacitation and protein tyrosine phosphorylation, Mol. Reprod. Dev. 69 (2004) 428-435.

[12] J.M. Bedford, M.C. Chang, Removal of decapacitation factor from seminal plasma by high-speed centrifugation, Am. J. Physiol. 202 (1962) 179-181.

[13] S.A. Adeoya-Osiguwa, L.R. Fraser, Evidence for $\mathrm{Ca}(2+)$-dependent ATPase activity, stimulated by decapacitation factor and calmodulin, in mouse sperm, Mol. Reprod. Dev. 44 (1996) 111-120.

[14] B.K. Davis, Decapacitation and recapacitation of rabbit spermatozoa treated with membrane vesicles from seminal plasma, J. Reprod. Fertil. 41 (1974) 241-244.

[15] B.K. Davis, N.V. Davis, Binding by glycoproteins of seminal plasma membrane vesicles accelerates decapacitation in rabbit spermatozoa, Biochim. Biophys. Acta 727 (1983) 70-76.

[16] L.A. Eng, G. Oliphant, Rabbit sperm reversible decapacitation by membrane stabilization with a highly purified glycoprotein from seminal plasma, Biol. Reprod. 19 (1978) 1083-1094.

[17] S.T. Mortimer, M.A. Swan, D. Mortimer, Effect of seminal plasma on capacitation and hyperactivation in human spermatozoa, Hum. Reprod. 13 (1998) 2139-2146.

[18] L.R. Fraser, Interactions between a decapacitation factor and mouse spermatozoa appear to involve fucose residues and a GPI-anchored receptor, Mol. Reprod. Dev. 51 (1998) 193-202.

[19] C.H. Lopes, M.N. Mazzini, H. Tortorella, R.A. Konrath, A. Brandelli, Isolation, partial characterization and biological activity of mannosyl glycopeptides from seminal plasma, Glycoconj. J. 15 (1998) 477-481.

[20] D. Montagnon, B. Valtat, F. Vignon, M.H. Koll-Back, Secretory proteins of human seminal vesicles and their relationship to lipids and sugars, Andrologia 22 (Suppl. 1) (1990) 193-205.

[21] M. Villemure, C. Lazure, P. Manjunath, Isolation and characterization of gelatin-binding proteins from goat seminal plasma, Reprod. Biol. Endocrinol. 1 (2003) 39.

[22] Z. Dostalova, J.J. Calvete, L. Sanz, E. Topfer-Petersen, Quantitation of boar spermadhesins in accessory sex gland fluids and on the surface of epididymal, ejaculated and capacitated spermatozoa, Biochim. Biophys. Acta 1200 (1994) 48-54.

[23] J.E. Parks, S.R. Hough, Platelet-activating factor acetylhydrolase activity in bovine seminal plasma, J. Androl. 14 (1993) 335339.

[24] L.C. Yu, J.L. Chen, W.B. Tsai, Y.H. Chen, Primary structure and characterization of an androgen-stimulated autoantigen purified from mouse seminal-vesicle secretion, Biochem. J. 296 (1993) 571576. 
[25] L.C. Yu, Y.L. Hsiao, Y.H. Yang, M. Lin, Y.H. Chen, The genomic structure of a mouse seminal vesicle autoantigen, Biochem. Biophys. Res. Commun. 231 (1997) 106-110.

[26] Y.H. Huang, S.T. Chu, Y.H. Chen, Seminal vesicle autoantigen, a novel phospholipid-binding protein secreted from luminal epithelium of mouse seminal vesicle, exhibits the ability to suppress mouse sperm motility, Biochem. J. 343 (1999) 241-248.

[27] Y.H. Huang, C.W. Luo, L.C. Yu, S.T. Chu, Y.H. Chen, The protein conformation and a zinc-binding domain of an autoantigen from mouse seminal vesicle, Biophys. J. 69 (1995) 2084-2089.

[28] Y.H. Huang, S.T. Chu, Y.H. Chen, A seminal vesicle autoantigen of mouse is able to suppress sperm capacitation-related events stimulated by serum albumin, Biol. Reprod. 63 (2000) 1562-1566.

[29] C.R. Ward, B.T. Storey, Determination of the time course of capacitation in mouse spermatozoa using a chlortetracycline fluorescence assay, Dev. Biol. 104 (1984) 287-296.

[30] J.A. Thomas, R.N. Buchsbaum, A. Zimniak, E. Racker, Intracellular $\mathrm{pH}$ measurements in Ehrlich ascites tumor cells utilizing spectroscopic probes generated in situ, Biochemistry 18 (1979) 2210-2218.

[31] P.E. Visconti, J.L. Bailey, G.D. Moore, D. Pan, P. Olds-Clarke, G.S Kopf, Capacitation of mouse spermatozoa. I. Correlation between the capacitation state and protein tyrosine phosphorylation, Development 121 (1995) 1129-1137.

[32] I.A. Demarco, F. Espinosa, J. Edwards, J. Sosnik, J.L. DeLa VegaBeltran, J.W. Hockensmith, G.S. Kopf, A. Darszon, P.E. Visconti, Involvement of a $\mathrm{Na}^{+} / \mathrm{HCO}^{-}{ }_{3}$ cotransporter in mouse sperm capacitation, J. Biol. Chem. 278 (2003) 7001-7009.

[33] Y. Zeng, J. Oberdorf, H. Florman, pH regulation in mouse sperm: identification of $\mathrm{Na}(+)-, \mathrm{Cl}(-)$-, and $\mathrm{HCO}_{3}(-)$-dependent and arylaminobenzoate-dependent regulatory mechanisms and characterization of their roles in sperm capacitation, Dev. Biol. 173 (1996) 510 520.

[34] P.E. Visconti, G.D. Moore, J.L. Bailey, P. Leclerc, S.A. Connors, D. Pan, P. Olds-Clarke, G.S. Kopf, Capacitation of mouse spermatozoa. II. Protein tyrosine phosphorylation and capacitation are regulated by a cAMP-dependent pathway, Development 121 (1995) 1139-1150.

[35] P. Kalab, P. Visconti, P. Leclerc, G.S. Kopf, p95, the major phosphotyrosine-containing protein in mouse spermatozoa, is a hexokinase with unique properties, J. Biol. Chem. 269 (1994) 38103817.

[36] D.L. Garbers, D.J. Tubb, R.V. Hyne, A requirement of bicarbonate for $\mathrm{Ca} 2+$-induced elevations of cyclic AMP in guinea pig spermatozoa, J. Biol. Chem. 257 (1982) 8980-8984.
[37] N.B. Garty, Y. Salomon, Stimulation of partially purified adenylate cyclase from bull sperm by bicarbonate, FEBS Lett. 218 (1987) 148-152.

[38] N. Okamura, Y. Tajima, A. Soejima, H. Masuda, Y. Sugita, Sodium bicarbonate in seminal plasma stimulates the motility of mammalian spermatozoa through direct activation of adenylate cyclase, J. Biol. Chem. 260 (1985) 9699-9705.

[39] Y. Chen, M.J. Cann, T.N. Litvin, V. Iourgenko, M.L. Sinclair, L.R. Levin, J. Buck, Soluble adenylyl cyclase as an evolutionarily conserved bicarbonate sensor, Science 289 (2000) 625-628.

[40] G. Wennemuth, A.E. Carlson, A.J. Harper, D.F. Babcock, Bicarbonate actions on flagellar and $\mathrm{Ca}^{2+}$-channel responses: initial events in sperm activation, Development 130 (2003) 1317-1326.

[41] H.L. Galantino-Homer, P.E. Visconti, G.S. Kopf, Regulation of protein tyrosine phosphorylation during bovine sperm capacitation by a cyclic adenosine $3^{\prime} 5^{\prime}$-monophosphate-dependent pathway, Biol. Reprod. 56 (1997) 707-719.

[42] T. Hunter, Tyrosine phosphorylation: past, present and future, Biochem. Soc. Trans. 24 (1996) 307-327.

[43] S. Ficarro, O. Chertihin, V.A. Westbrook, F. White, F. Jayes, P. Kalab, J.A. Marto, J. Shabanowitz, J.C. Herr, D.F. Hunt, P.E. Visconti, Phosphoproteome analysis of capacitated human sperm. Evidence of tyrosine phosphorylation of A kinase-anchoring protein 3 and valosin-containing protein/p97 during capacitation, J. Biol. Chem. 278 (2003) 11579-11589.

[44] A.J. Begley, P. Quinn, Decapacitation factors in semen, Clin. Reprod. Fertil. 1 (1982) 167-175.

[45] C.Y. Hong, B.N. Chang, P. Turner, Calcium ion is the key regulator of human sperm function, Lancet 2 (1984) 1449-1451.

[46] C.E. Coronel, M.L. Novella, D.E. Winnica, H.A. Lardy, Isolation and characterization of a 54-kilodalton precursor of caltrin, the calcium transport inhibitor protein from seminal vesicles of the rat, Biol. Reprod. 48 (1993) 1326-1333.

[47] G. Wennemuth, D.F. Babcock, B. Hille, Calcium clearance mechanisms of mouse sperm, J. Gen. Physiol. 122 (2003) 115-128.

[48] S.B. Sleight, P.V. Miranda, N. Plaskett, B. Maier, J. Lysiak, H. Scrable, J.C. Herr, P.E. Visconti, Isolation and proteomic analysis of mouse sperm detergent-resistant membrane fractions. evidence for dissociation of lipid rafts during capacitation, Biol. Reprod. 73 (2005) 721-729.

[49] L.J. Pike, Lipid rafts: bringing order to chaos, J. Lipid Res. 44 (2003) 655-667.

[50] T. Fujimoto, Calcium pump of the plasma membrane is localized in caveolae, J. Cell Biol. 120 (1993) 1147-1157. 